
a new clothing production method. My research was focused on developing an articanal process thet makes clothing comparable to 3D printing. I drew on my research of human anatomy and the body to rethink the construction of clothing. My work is an analogy between body and clothing. My designs are based on human muscular weaves. Al my patterns are extracted from human anatomy to create a new, wearable skin. This method of construction allows people to wear their own anatomies, exposing the internal construction of their bodies. Each piece is entirely made of a single recycled thread. This experimental method is hand-crafted, whout capable of sewing machine. Because this process is handmade, the goel so $\mathrm{PhD}$ in fashion textiles

\section{Print the body.
Clothes printing project \\ Print the body.
Clothes printing project}

HOW TO CITE textile waste and proposes a different form of industrial customised clothing production.

Vicerial, Jeanne. 2018. "Print the body. Clothes printing project". Temes de disseny 34: 44-47.

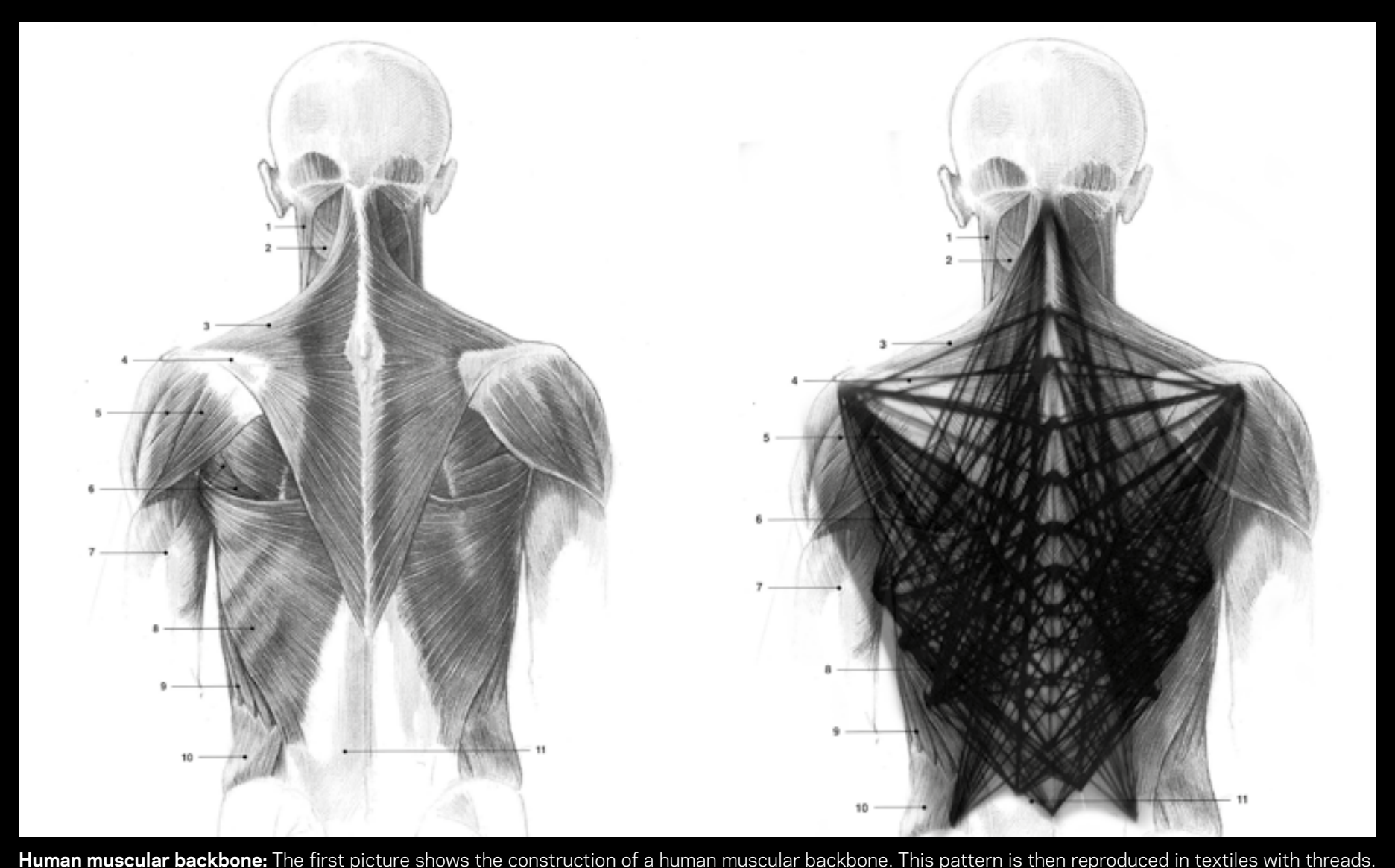

Human muscular backbone: The first picture shows the construction of a human muscular backbone. This pattern is then reproduced in textiles with threads.
The idea here is to recreate textili muscles to make a wearable muscular envelope. The work done here is like that of a garments surgeon. Weattempted to build
and

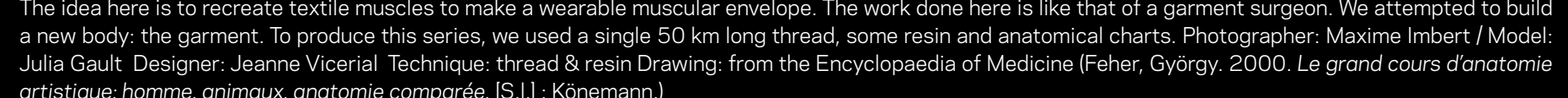
TEMES DE DISSENY \#34

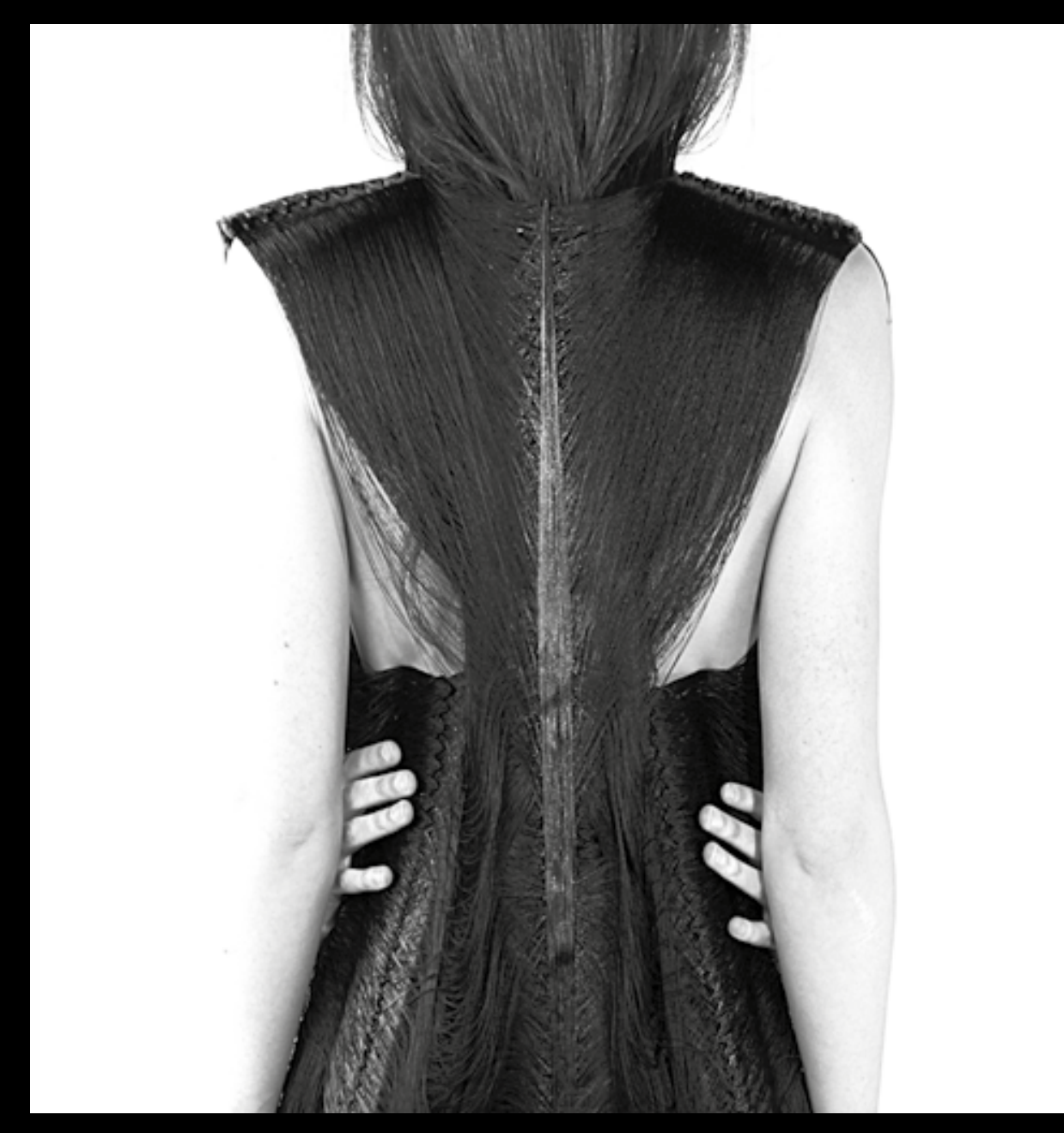

J. VICERIAL

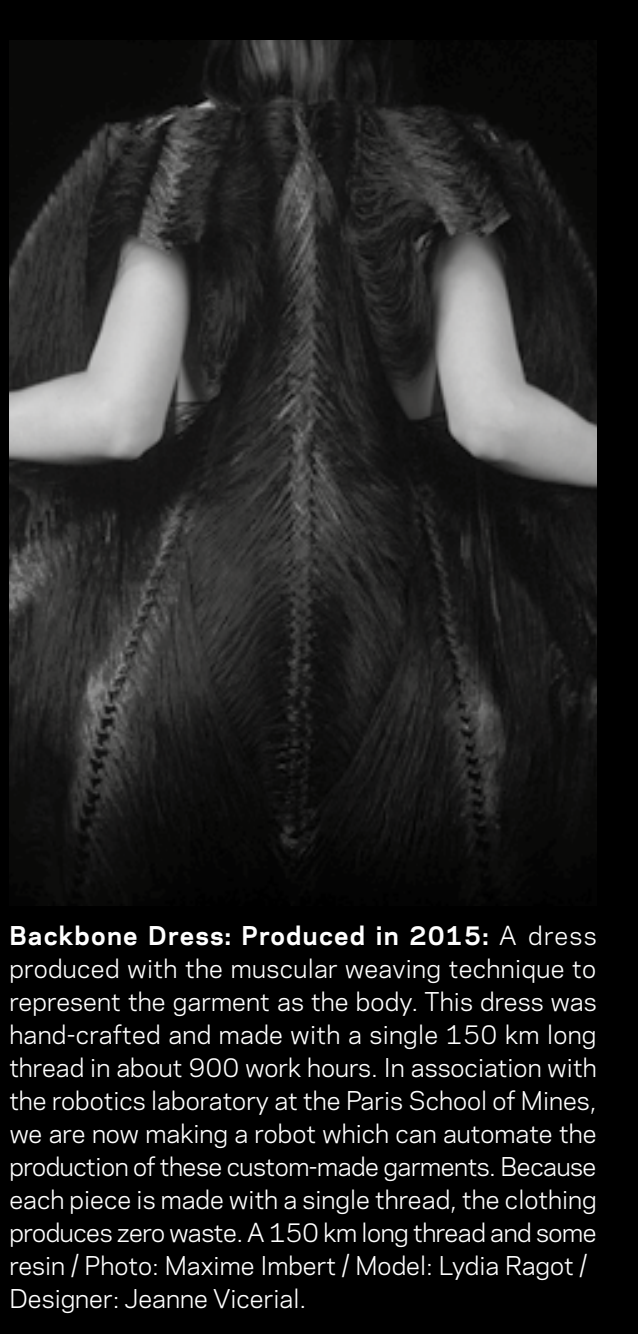

43 
